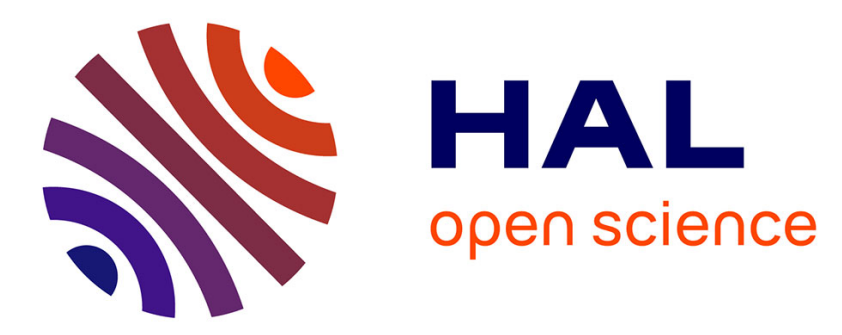

\title{
Resistance to fragmentation of recycled concrete aggregates
}

\author{
Riccardo Artoni, Bogdan Cazacliu, Erwan Hamard, Alexis Cothenet, Régis \\ Sebben Paranhos
}

\section{- To cite this version:}

Riccardo Artoni, Bogdan Cazacliu, Erwan Hamard, Alexis Cothenet, Régis Sebben Paranhos. Resistance to fragmentation of recycled concrete aggregates. Materials and structures, 2017, 11 (50), 12p. $10.1617 / \mathrm{s} 11527-016-0900-\mathrm{y}$. hal-01618247

\section{HAL Id: hal-01618247 \\ https://hal.science/hal-01618247}

Submitted on 17 Oct 2017

HAL is a multi-disciplinary open access archive for the deposit and dissemination of scientific research documents, whether they are published or not. The documents may come from teaching and research institutions in France or abroad, or from public or private research centers.
L'archive ouverte pluridisciplinaire HAL, est destinée au dépôt et à la diffusion de documents scientifiques de niveau recherche, publiés ou non, émanant des établissements d'enseignement et de recherche français ou étrangers, des laboratoires publics ou privés. 


\title{
Resistance to fragmentation of recycled concrete aggregates
}

\author{
Riccardo Artoni - Bogdan Cazacliu - Erwan Hamard • Alexis Cothenet • \\ Régis Sebben Parhanos
}

May 25, 2016. Materials and Structures 2017 (accepted).

\begin{abstract}
This work deals with the characterization of fragmentation of recycled concrete aggregate (RCA) by the Los Angeles test. The standard testing procedure for the Los Angeles index requires the measurement of the mass passing $1.6 \mathrm{~mm}$ after 500 revolutions of the drum. Questions arise on the significance of this measure for RCA as the resistances of the mortar, of the original aggregate and of their interface simultaneously affect the measurement result. In order to clarify the interpretation of such a measure, three aspects were investigated: the influence of the number of revolutions, the evolution of the full particle size distribution and the distribution of mortar in the fractions after the test. The results suggested that the fracture mechanisms are similar between recycled and natural aggregates with some quantitative differences. Recycled concrete aggregate was less resistant to fragmentation and displayed a non linear evolution of mass passing $1.6 \mathrm{~mm}$ with the number of revolutions. During fracture of RCA, mortar progressively accumulates in smaller fractions, with coarse fractions asymptotically behaving like natural aggregates. The analysis of the rate of breakage of the coarsest fraction appeared to be a richer indicator of crushability as a function of time and composition than the amount of the mass passing $1.6 \mathrm{~mm}$ : its typical evolution allows estimating a rate of breakage which correlates well with indirect measures of composition (water
\end{abstract}

This work was partially funded by the PN Récybéton and by the CAPES/COFECUB RE-MAUD project.

R. Artoni - B. Cazacliu · E. Hamard · A. Cothenet

LUNAM Université, IFSTTAR, MAST, GPEM, F-44340

Bouguenais, France

E-mail: riccardo.artoni@ifsttar.fr

R. Sebben Parhanos

UNIPAMPA - Campus Caçapava do Sul, Av. Pedro Anunciação,

111 - Vila Batista - Caçapava do Sul - RS - Brazil absorption and density). The possible existence of an asymptote in the rate of breakage of the coarsest fraction suggests that it can be used to estimate at the same time the resistance of the recycled aggregate and of its original natural component, and probably give an estimate of the amount of mortar.

\section{Introduction}

Recycling and reusing construction and demolition waste is one of the best methods to improve the environment (Blengini and Garbarino 2010) by easing landfill pressures and reducing demand of extraction. One major component of the construction and demolition waste is the concrete debris (Commissariat Général au Développement Durable 2011; Varela et al 2011). Further than lower quality applications like man-made reef, paving stones or protection of levee (Kawano 1995), the usual way to recycle concrete debris is the use as natural aggregate replacement in unbound pavement construction, backfilling or foundation materials (Tam and Tam 2006). More recently, reuse of recycled concrete aggregate (RCA) as natural aggregate replacement in new concrete (Buck 1973) is increasingly considered in practice (Rao et al 2007).

For suitable use of RCA, their knowledge and tests should refer to physical (geometry, water absorption, specific gravity, mechanical resistance to fragmentation, wear, surface abrasion), chemical (petrography, amount of chlorides and sulfates) and eventually environmental (leaching) characteristics (Oikonomou 2005). In particular for the resistance to fragmentation of RCA, many recent works suggest the use of the Los Angeles test: this concerns various applications, like backfilling materials (Rahman et al 2014), unbound pavement sub- 
base (Arulrajah et al 2014) or base course (Diagne et al 2015), recycled aggregate concrete (Yiu et al 2009; Paine and Dhir 2010), roller compacted concrete (Courard et al 2010), asphalt concrete (Pasandín and Pérez 2014). Recommendation for coarse recycled aggregate resistance to fragmentation categories for the use in concrete in the European standard EN 206-1 (2000) is based on the Los Angeles coefficient (LA) as specified in EN 1097-2 (2010) for natural coarse aggregate.

The Los Angeles (LA) test is an empirical measure of degradation of mineral aggregates of standard grading. The crushing action is produced by steel balls which cause impact on aggregates when mixed and rotated in a horizontal drum for a specific number of revolutions. The evolution of the particle size distribution is measured by the proportion of fine particles (smaller than 1.6 or $1.7 \mathrm{~mm}$ ) created during the test. The LA value corresponds to the percentage of the initial mass which has passed the $1.6 \mathrm{~mm}$ sieve. Extensively used in USA from decades (Amirkhanian et al 1991) in different versions, the LA test is in use in all European community for characterization of the mechanical behavior of aggregates (mainly 10/14 mm - i.e. the size range between 10 and $14 \mathrm{~mm}$ - but $4 / 6.3 \mathrm{~mm}$ and $6.3 / 10 \mathrm{~mm}$ are also accepted) and ballasts (ASTM C131 (2014) and EN 1097-2 (2010) for coarse aggregates, ASTM C535 (2013) and EN 13450 (2002) for large-size coarse aggregates). For $10 / 14 \mathrm{~mm}$ aggregates, the LA test is performed on a $5 \mathrm{~kg}$ feed, with 11 normalized steel balls, for $500 \mathrm{rev-}$ olutions of the drum.

Comminution theory (Bond 1952; von Rittinger 1867; Kick 1885; Wills and Atkinson 1993) is concerned with the relationship between the energy input and the particle size made from a given feed size. The energy input of the Los Angeles test involved in fragmentation can be roughly estimated from the free-fall height and the weight of the steel balls and aggregates (Bach 2013). An increase in the number of steel balls or an increase in the number of rotations yields an increase of the energy input. Given that, for the same energy input, the LA value increases when the feed aggregate has smaller size, the standard adapts (decreases) the number of balls for lower size gradings. Also, the test for railway ballast defined in EN 13450 (2002) uses the same test drum, 12 steel balls, $10 \mathrm{~kg}$ of $31.5 / 50 \mathrm{~mm}$ aggregate, and calls for 1000 revolutions of the drum. However, even when adapting the energy input by varying such process parameters, the LA value can depend on aggregate size (Panet and Tourenq 1971).

The LA value is sensitive to variations of the shape of aggregates (Kazi and Al-Molki 1982) but the impact of variations in petrographic composition on the degree of fragmentation proved significantly stronger than the impact of shape (Bach 2013). Also, the influence of the textural characteristics on the engineering properties appears to be more important than the mineralogy (Tuğrul and Zarif 1999). Indeed, micro crack size distribution, grain shape and grain size show strong correlations with the mechanical properties (Liu et al 2004). The behavior is increasingly complex for recycled aggregates, given the variability of their constituents (stone, mortar, clay brick, ... ) and of the composition, the latter depending on the quality of the original concrete and on the degree of liberation.

As a general trend, the Los Angeles coefficient decreases with the percentage of masonry (Barbudo et al 2012; Cameron et al 2012; Diagne et al 2015). For recycled concrete aggregate, the presence of mortar induces a higher LA value than for the corresponding original natural aggregate (Zega et al 2010); then, the higher the mortar content the higher the LA value (De Juan and Gutiérrez 2009). The quality of the crushed concrete has also significant impact on the Los Angeles test result. De Juan and Gutiérrez (2009) report a correlation between the strength of the parent concrete and the LA value of RCA. The greatest fragmentation in RCA occurs in concretes with a weaker matrix (Mostafa Tavakoli and Parviz Soroushian 1996; Hansen, Torben C. and Narud, Henrik 1983; Zega et al 2010). Mortar content and quality of concrete are however often two interdependent parameters, because mortar content in RCA depends on the history of the aggregates, and RCA are produced by crushing and classification: for example, for a similar crushing procedure and size of the original natural aggregate, the RCA produced from the stronger concrete contained a relatively higher amount of mortar (Belin et al 2014) but with a better adherence of mortar to natural aggregate (Akbarnezhad et al 2013).

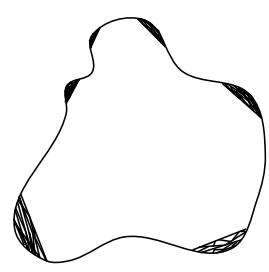

(a)

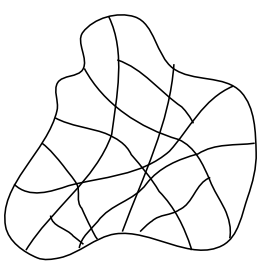

(b)

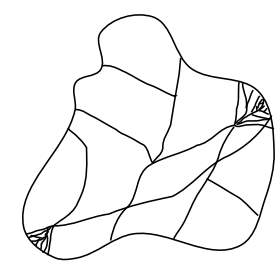

(c)
Fig. 1 Principal mechanisms of particle breakage, after King (2001): (a) chipping and attrition, (b) shattering, (c) cleavage.

During a fragmentation test, several mechanisms of fracture may be involved (e.g. cleavage, shattering, chipping and attrition) (King 2001), as exemplified in Figure 1. The relative importance of each mechanism depends on the process parameters (e.g. impact energy), on particle size, on mineralogical texture and 
composition. In view of this, the los Angeles value does not provide an accurate description for the sample's resistance to fragmentation.

In order to characterize better the mechanisms taking place during the process, more information on the evolution of the particle size distribution (PSD) is needed. In this perspective, Erichsen (2015) proposed to measure both LA value and residual LA value (aggregate still in the initial grading), then to follow the evolution of the granular size for different number of rotations of the drum. In order to better understand the indistinct behavior of the original natural aggregate and of the attached mortar with respect with the mechanical loading in the Los Angeles testing machine, this paper presents experiments on natural and recycled concrete aggregates. The full PSD is measured at different numbers of revolutions for different initial gradings. Water absorption capacity and density are measured at different numbers of revolutions of the drum in order to correlate the Los Angeles value with an estimation of the attached mortar content remaining on the recycled concrete particles. An analysis based on comminution modeling is developed, allowing to evaluate the breakage rate and the distribution of progeny particles with some confidence; the analysis helps to quantify kinetics of breakage and to understand the main mechanisms undergoing during the LA test.

\section{Materials \& Methods}

\subsection{Materials}

The materials used in this work are recycled concrete aggregates in the range $4 / 20 \mathrm{~mm}$, supplied by the PN Recybéton, commercially produced by the "Gonesse Recycling Centre" located in France.

Inspiring on the norm EN 1097-2 (2010), the materials were sieved and recomposed in order to form four size fractions, corresponding to the size ranges : $4 / 6.3 \mathrm{~mm} ; 6.3 / 10 \mathrm{~mm} ; 10 / 14 \mathrm{~mm} ; 14 / 20 \mathrm{~mm}$. The granulometry of the four recomposed samples is given in Table 1. Two samples of natural aggregates (gneiss, in size ranges $4 / 6.3 \mathrm{~mm}$ and 10/14 $\mathrm{mm}$ ), recomposed with the same proportions as for recycled aggregates, were also used for comparison.

\subsection{Los Angeles testing machine}

In order to measure the crushability of recycled aggregates, a Los Angeles testing machine was used (EN 1097-2 2010). The machine (a photo of which is given in Fig. 2) consists of a steel drum (inner diameter $\mathrm{D}=711$

\begin{tabular}{|c|c|c|}
\hline Size range & $35 \%$ fraction & $65 \%$ fraction \\
\hline $4 / 6.3 \mathrm{~mm}$ & $4 / 5 \mathrm{~mm}$ & $5 / 6.3 \mathrm{~mm}$ \\
$6.3 / 10 \mathrm{~mm}$ & $6.3 / 8 \mathrm{~mm}$ & $8 / 10 \mathrm{~mm}$ \\
$10 / 14 \mathrm{~mm}$ & $12.5 / 14 \mathrm{~mm}$ & $10 / 12.5 \mathrm{~mm}$ \\
$14 / 20 \mathrm{~mm}$ & $14 / 16 \mathrm{~mm}$ & $16 / 20 \mathrm{~mm}$ \\
\hline
\end{tabular}

Table 1 Composition of the four recomposed size fractions, inspired by the norm EN 1097-2 (2010).

$\mathrm{mm}$, length $\mathrm{L}=508 \mathrm{~mm}$ ), rotating between 31 and 33 rpm, and of a fragmentation charge composed of steel balls with a mass comprised between $400 \mathrm{~g}$ and $445 \mathrm{~g}$, and a diameter of approximately $47 \mathrm{~mm}$. For all the tests, $5 \mathrm{kgs}$ of aggregates and 11 steel balls were feeded at the beginning. The number of revolutions was defined before the test.

It is important to add a comment on the type of stresses

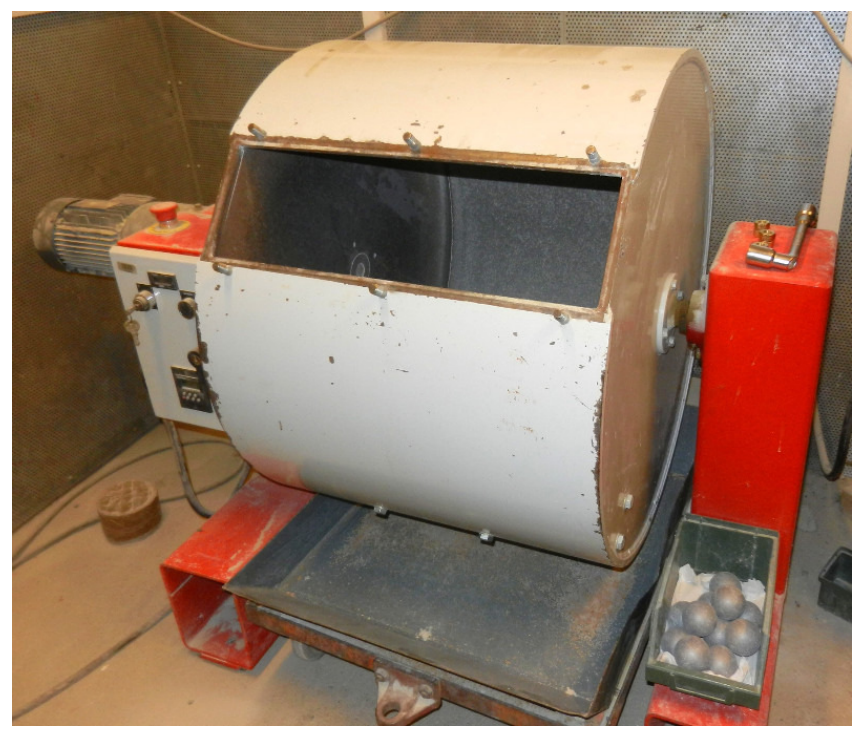

Fig. 2 Picture of the Los Angeles testing machine used in this work.

which are applied by the grinding media (the steel balls) to the aggregate particles during the Los Angeles test. First of all, the drum is rotating rapidly: the Froude number is $\operatorname{Fr}=\frac{\omega^{2} R}{g} \approx 0.4$, which means that the centrifugal force acting on a particle in contact with the drum wall is nearly half its weight. The speed of rotation and the presence of a lifter imply a cataracting motion of the solids in the drum. Moreover, the degree of filling of the drum is very low (less than $5 \%$ ). This means that aggregate particles are stressed (and eventually crushed) by the impact of steel balls falling from the lifter on a shallow layer of aggregates lying on the wall. On the basis of these considerations, we argue that the Los Angeles tests should give results similar to the repetition of a drop weight test (Tavares 2007). 


\begin{tabular}{|c|c|c|}
\hline Aggregates sample & $W A, 2 \mathrm{~h}(\%)$ & $\rho_{p}(\mathrm{~g} / \mathrm{cm} 3)$ \\
\hline $4 / 6.3 \mathrm{~mm}$, natural & 0.4 & 2.63 \\
$10 / 14 \mathrm{~mm}$, natural & 0.3 & 2.64 \\
4/6.3 mm, recycled & 5.5 & 2.29 \\
$10 / 14 \mathrm{~mm}$, recycled & 4.9 & 2.28 \\
\hline
\end{tabular}

Table 2 Water absorption and particle density of 4/6.3 and $10 / 14$ samples of feeded materials.

\subsection{Water Absorption \& particle density}

Measurements of water absorption and particle density were performed in order to obtain an indirect and qualitative estimate of the amount of mortar existing in the recycled aggregates. Mortar is generally porous and less dense than natural aggregates, therefore an increasing mortar content in the aggregates yields an increasing water absorption and a decreasing particle density. Water absorption $W A$ and particle density $\rho_{p}$ were measured with a water pycnometer following the procedure defined in the norm EN 1097-6 (2013). Tests were made with an amount of aggregate samples around $1 \mathrm{~kg}$. Different soaking times were used; results presented in this work were obtained with a soaking time of 2 hours. Water absorption is defined as the ratio between the weight of water absorbed into the particle (with the exclusion of the quantity trapped at the surface) and the dry weight of the particle. By means of the same test, the oven dried particle density was also measured, defined as the ratio between the dry weight of the particle and the volume including also the open pores. Values of $W A$ and $\rho_{p}$ for $4 / 6.3 \mathrm{~mm}$ and $10 / 14 \mathrm{~mm}$ feed samples are reported in Tab. 2 .

\subsection{Granulometry}

The particle size distribution of the feeds and of the products of the fragmentation was measured by sieving. The materials were in some cases sampled by quartering before sieving. Dry sieving by hand was performed, following the norm EN 933-1 (2012), with a sieve opening sequence of $[0.5,1.25,1.6,2,3.15,4,5,6.3,8,10$, $11.2,12.5,14,16,20] \mathrm{mm}$ for $10 / 14 \mathrm{~mm}$ samples, and of $[0.5,0.8,0.12,1,1.25,1.6,2,2.5,3.15,4,5,5.6,6.3$, $8,10] \mathrm{mm}$ for $4 / 6.3$ samples.

\subsection{Experimental plan}

The evaluation of the kinetics of size reduction phenomena occuring during a test in the Los Angeles machine has been performed in two steps.

In the first phase the amount of material passing the $1.6 \mathrm{~mm}$ sieve was chosen as simple indicator of the degree of crushing, as in the norm EN 1097-2 (2010) Six types of aggregates were processed:

- recycled aggregate of size ranges $4 / 6.3,6.3 / 10,10 / 14$ and $14 / 20 \mathrm{~mm}$,

- natural aggregates $6.3 / 10$ and 10/14 mm,

for different number of drum revolutions : 50, 100, 200, 300, 500, 750, 1000, 2000, 3000. This step allowed to test the approach prescribed by the norm (which was developed for natural aggregates) for the case of recycled aggregates, and to identify relevant values of the number of revolutions, and initial size fractions to be further investigated.

In the second phase of the study the granulometry was measured before and after the test. Four types of aggregates were tested:

- recycled aggregate of size ranges $4 / 6.3$, and 10/14 $\mathrm{mm}$,

- natural aggregates 6.3/10 and 10/14 mm,

at 100, 300, 5001000 and 2000 revolutions. Water absorption and particle density were measured before the tests (see Table 2). In addition, for the 10/14 mm recycled aggregates sample, from the products of the fragmentation after the given number of revolutions, three size ranges $(4 / 6.3 \mathrm{~mm}, 6,3 / 10 \mathrm{~mm}$ and $10 / 14 \mathrm{~mm})$ were extracted ; the water absorption and particle density measurements were performed on these subclasses in order to evaluate the change in composition by size range during the fragmentation.

\section{Results}

3.1 Mass passing $1.6 \mathrm{~mm}$ vs number of revolutions

In figure 3 we collect data of the fraction of the initial mass passing the $1.6 \mathrm{~mm}$ sieve at different numbers of revolutions, for different initial size fractions of recycled aggregates and natural aggregates. Please note that $4 / 6.3 \mathrm{~mm}$ natural aggregates data are extracted from the second phase of the study, therefore less points are available, but the trend is clear.

The mass passing $1.6 \mathrm{~mm}$ indicator measures the production of small fragments. Several informations can be drawn from the figure. At first, the rate of formation of fragments less than $1.6 \mathrm{~mm}$ is higher for recycled than for natural aggregates. Then, while for 10/14 mm natural aggregates this indicator seems to be a linear function of the number of revolutions up to $2000 \mathrm{rev}-$ olutions, for recycled materials there is a strong non linearity, with the slope of the profile clearly decreasing with the number of revolutions. Both of these aspects may be related to the presence of mortar in recycled 


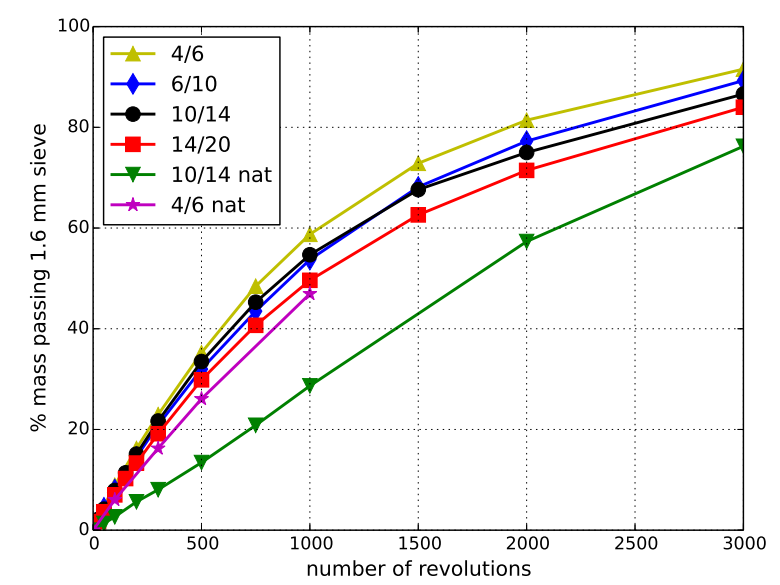

Fig. 3 Percentage of initial mass passing the $1.6 \mathrm{~mm}$ sieve vs number of revolutions, for 4 different initial granulometries of recycled aggregates and for $4 / 6.3 \mathrm{~mm}$ and $10 / 14 \mathrm{~mm}$ natural aggregate samples.

aggregates, which generally gives a lower resistance to fragmentation to the aggregates (Zega et al 2010). We expect mortar to be preferentially broken and therefore the coarsest fractions to become poor in mortar during the test: therefore it is not surprising to see that the resistance to fragmentation increases with the number of revolutions.

The non linearity is however also related to the fact that evidently when reaching values near to $100 \%$, the curve has an asymptote (for natural aggregates too); so, given that recycled aggregates are less resistant, the small fragments are produced at a higher rate and their amount gets close to the asymptote earlier.

The rate of formation of particles smaller than 1.6 $\mathrm{mm}$ depends also on the initial size fraction. The dependence of the mass passing $1.6 \mathrm{~mm}$ curve on particle size is expected (Panet and Tourenq 1971) since the threshold defining the indicator was kept fixed, while the size fraction was varied. In order to perform consistent analyses, the ratio of the threshold and of the feed size should be fixed. This is exemplified in Fig. 4, where a threshold at $4 \mathrm{~mm}$ sieve is considered for the 10/14 $\mathrm{mm}$ fractions (data from PSDs discussed in the following subsection are used for this purpose). This threshold was chosen because it gives the same ratio threshold / lower bound of the initial size fraction as $1.6 \mathrm{~mm}$ with respect to $4 / 6.3 \mathrm{~mm}$ size range. We can see that the difference between natural aggregates' curves is clearly removed, while recycled aggregates curves are inversed with respect to Fig. 3 (but still display not too large differences).

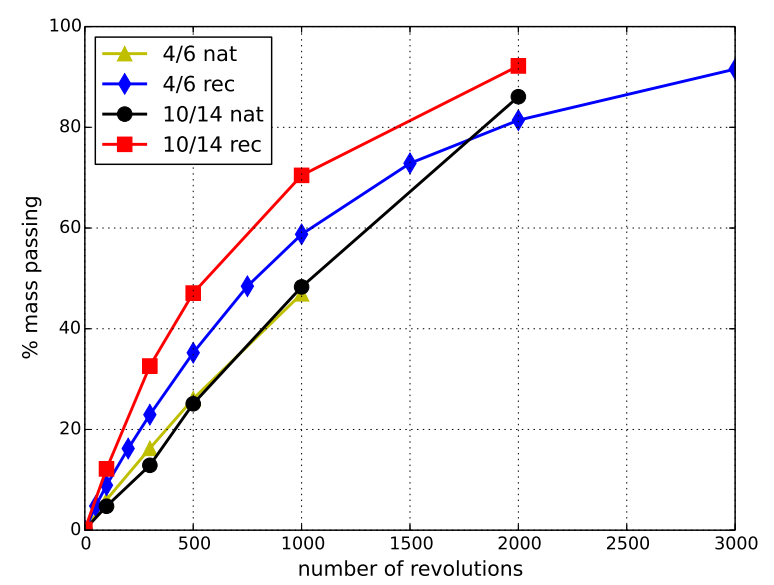

Fig. 4 Percentage of initial mass passing a threshold sieve vs number of revolutions, for $4 / 6.3 \mathrm{~mm}$ and $10 / 14 \mathrm{~mm}$, natural and recycled aggregate samples. Threshold sieve is $4 \mathrm{~mm}$ for $10 / 14$ $\mathrm{mm}$ aggregates and $1.6 \mathrm{~mm}$ for $4 / 6.3 \mathrm{~mm}$ aggregates.

\subsection{PSD vs number of revolutions}

The fraction of the initial mass passing a given threshold (e.g. $1.6 \mathrm{~mm}$ in EN 1097-2 (2010)) can be used as a quick indicator for the resistance of the material based on the production of small fragments. However, during the fragmentation process, the smallest class receives fragments from all the higher classes, so this indicator lumps together a large amount of information which it may be difficult to interpret. In addition, the non linearity observed for recycled materials is a phenomenon that cannot be fully understood and characterized without a deeper analysis; it is clear that given this non linearity the use of a characteristic value of the mass passing $1.6 \mathrm{~mm}$ (for example the value at 500 revolutions) can be criticized for recycled aggregates since its value will depend on too many parameters (mortar content and its mechanical behavior, initial granulometry and behavior of intermediate size grains created during the loading) and will therefore give an unclear reference for the material.

For these reasons, in the present study, the full particle size distribution (PSD) was measured at different numbers of revolutions, for recycled and natural aggregates, in order to better characterize the evolution of the sample with time. In Figure 5, we display the cumulative PSDs for natural and recycled aggregates in size ranges $4 / 6.3 \mathrm{~mm}$ and $10 / 14 \mathrm{~mm}$. For all materials the evolution of the PSD is similar, with a slower evolution for natural aggregates. The coarser aggregates display larger difference in kinetics between natural and recycled samples, as previously observed with respect to the amount of fines (Figure 3). The evolution of the PSD 
(a)

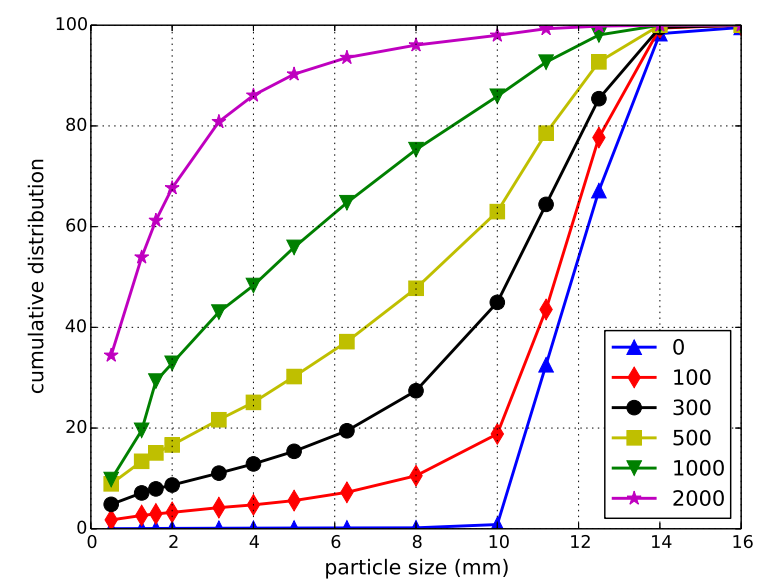

(c)

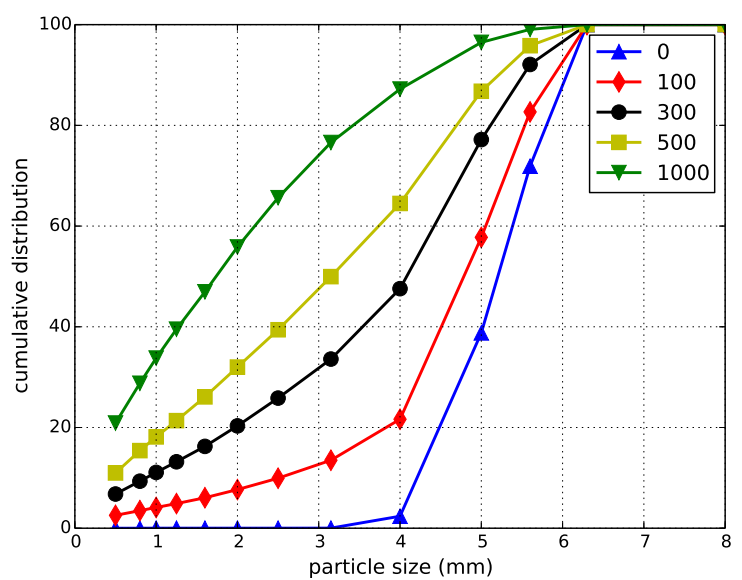

(b)

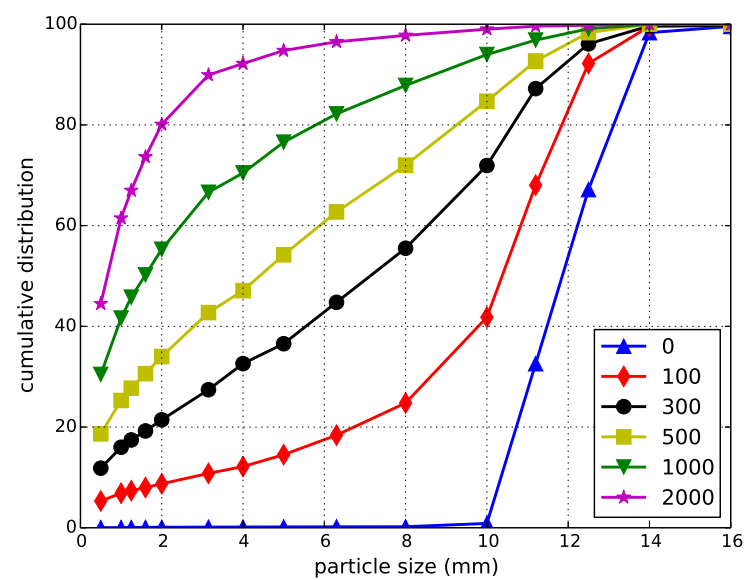

(d)

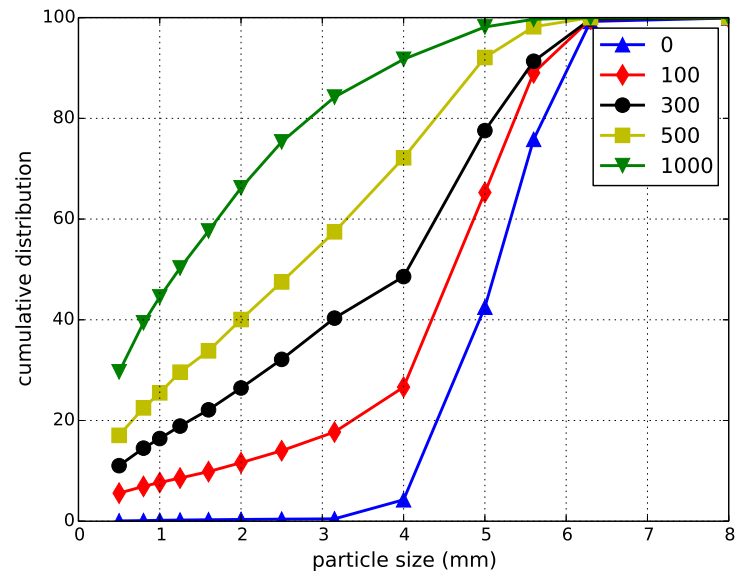

Fig. 5 Cumulative distributions of particle size for (a) natural 10/14 mm aggregates, (b) recycled 10/14 mm aggregates, (c) natural $4 / 6.3 \mathrm{~mm}$ aggregates, (d) recycled $4 / 6.3 \mathrm{~mm}$ aggregates. For $4 / 6.3 \mathrm{~mm}$ aggregates the test was performed only up to 1000 revolutions.

suggests that crushing events produce a broad distribution of particle sizes. However, from a qualitative analysis of the PSDs, it is difficult to discuss about the differences between recycled and natural aggregates concerning the size distribution of progeny particles. This can only be obtained by means of analyses inspired by comminution theories, as it will be done in Section 4 .

\section{$3.3 W A$ and $\rho_{p}$ vs number of revolutions}

Water absorption is an indirect measure of the amount of mortar existing in the recycled aggregates. In figure 6 we analyse the water absorption of three different (coarse) size classes extracted from an initial 10/14 sample after different numbers of revolutions. The water absorption value decreases with the number of revolutions for the three coarse fractions; the smallest classes display higher water absorption.
This can be explained by the fact that since mortar is less resistant, broken particles will be richer in mortar, and that the smallest size range will progressively remove a large part of the mortar of the other classes. This is confirmed by the fact that, after a given number of revolutions, the different size fractions reach a value of water absorption which is in the range displayed by natural aggregates.

Another indirect measure of mortar content is density. Mortar is generally less dense than aggregates, so we expect less dense samples to be richer in mortar. In figure 7 , as for the water absorption, we analyse the density of the three size classes extracted from the initial 10/14 mm sample after different numbers of revolutions. The density increases with the number of revolutions for the three coarse fractions; the smaller classes display lower density. This confirms the picture suggested by water absorption data: during the process 


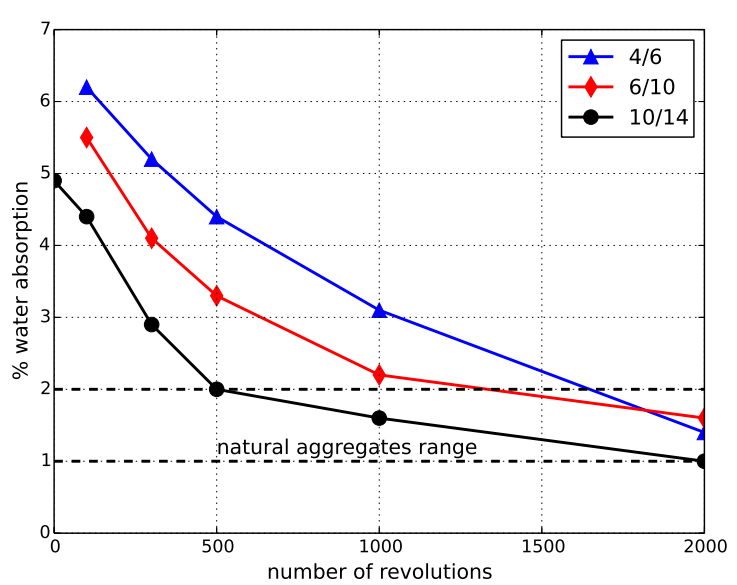

Fig. 6 Fragmentation test of an initial 10/14 mm recycled aggregates sample. Water absorption of different size fractions vs number of revolutions.

mortar is preferentially found in finer classes and coarse fractions become progressively poor in mortar. Similar trend was reported in literature for the composition of recycled concrete aggregate after crushing: the smaller the particle size, the higher the mortar content (Belin et al 2014; Zega et al 2010).

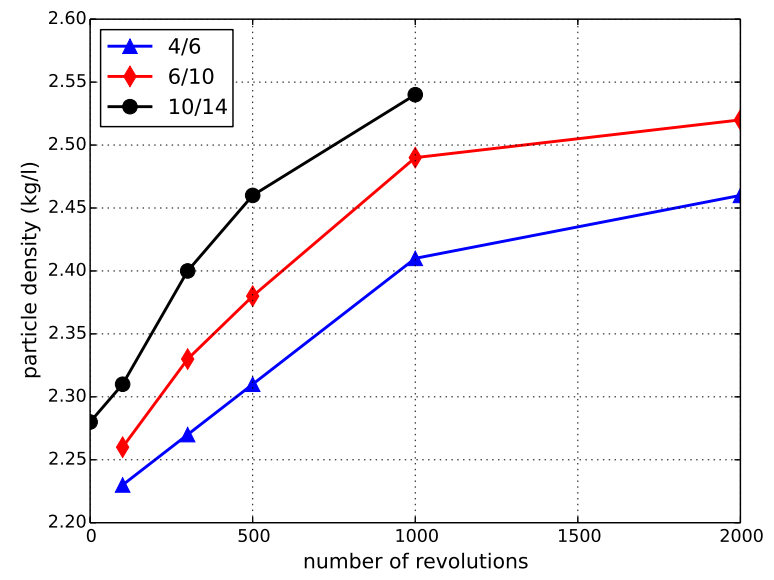

Fig. 7 Fragmentation test of an initial 10/14 mm recycled aggregates sample. Oven dried particle density of different size fractions vs number of revolutions.

The accumulation of mortar in the finer fractions and the liberation of natural aggregates is evident also from a visual inspection of the materials after the test. As an example, in Figure 8 we display the appearance of an initial 10/14 $\mathrm{mm}$ recycled aggregates sample before and after 2000 revolutions of the drum; it is evident that finer fractions are richer in mortar, and that coarser fractions contain nearly liberated natural aggregates.

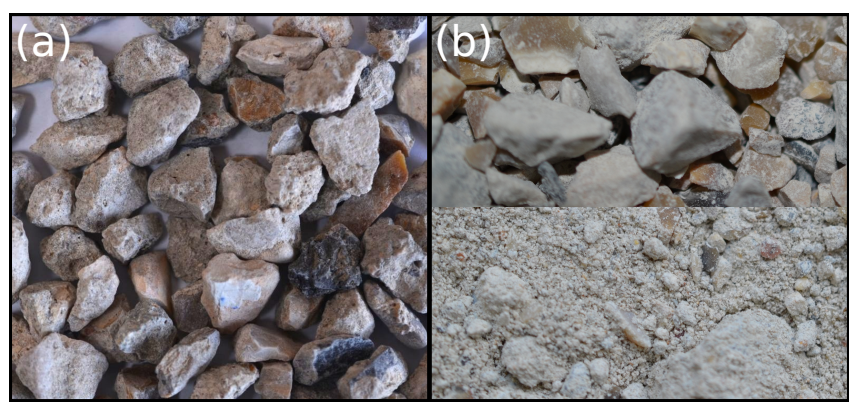

Fig. 8 Fragmentation test of an initial 10/14 mm recycled aggregates sample. Pictures of aggregates (a) before and (b) after 2000 revolutions of the drum (top: zoom on a coarse fraction, bottom: zoom on a finer fraction). Accumulation of mortar in the fines and liberation of natural aggregates is evident.

The good correlation between water absorption and density data is shown in figure 9 , which combines the previous figures. This supports the fact that both of these measurements can be taken as an indicator for the mortar content. Both measures depend on also other properties of the material and therefore some reference point is always needed in order to extract any quantitative information.

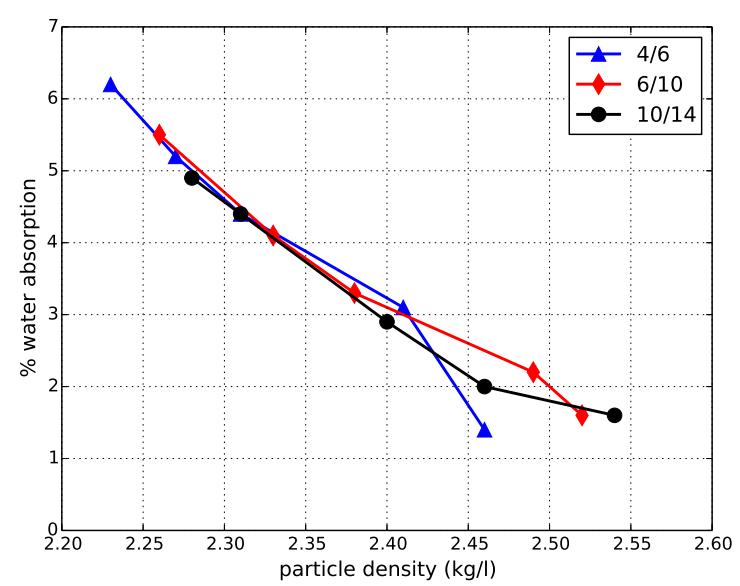

Fig. 9 Fragmentation test of an initial 10/14 mm recycled aggregates sample. Correlation between particle density and water absorption measurements for different size fractions.

\section{Discussion}

The previous section allowed to understand the main features of the processes ongoing in the Los Angeles testing machine for natural and recycled materials. In the following, PSD data will be analysed more deeply in order to get more details on the fragmentation phenomena involved in the test. 
A first comment is needed on the indicator used as a measure of resistance to fragmentation. In the norm EN 1097-2 (2010), the value of mass passing $1.6 \mathrm{~mm}$ is used as an indicator of the crushability of aggregates; however, from the results given in the previous section we can infer that, when the composition of the material is heterogeneous, the interpretation of the so-called LA value (the fraction of the mass passing $1.6 \mathrm{~mm}$ at 500 revolutions) can be tricky. In addition, the optimal test for recycled aggregates should characterize at the same time the composite material and the constituents (mortar, aggregates) in order to understand the resistance of the full system and of its components. The mass passing $1.6 \mathrm{~mm}$ is not very well for this purpose since it tells us that the crushability changes with time, but the presence of an asymptote at a large number of revolutions does not allow an easy determination of the properties of the aggregates phase.

For this reason, in the following we will propose a different approach: instead of measuring the evolution of fines, we will analyse the evolution of the coarse initial fraction (which is related to the so-called LA residual value (Erichsen 2015)). According to comminution theory, breakage can be modeled as a first order process, the rate of which depends on particle size and composition. Therefore it is evaluated here if the breakage rate of the coarsest fraction can be taken as a measure of crushability, and of its dependence on composition.

In figure 10, the evolution of the initial size fraction at different numbers of revolutions, derived from the PSD, is displayed for both natural and recycled 10/14 $\mathrm{mm}$ aggregates. Clearly recycled materials break at a higher rate than natural ones. As it is evident from the inlet, the evolution of natural aggregates is exponential, which confirms the supposition of a first order process. As the slope of the curve in the inlet shows, for recycled materials the rate of breakage decreases with time, up to a certain number of revolutions (between 500 and $1000)$, when it takes a constant value which is comparable to the value of natural aggregates.

It seems therefore that the rate of breakage of the initial size fraction is an interesting measure of crushability which may highlight the changes in composition occurring during the process. In order to get a quantitative estimate of the rate of breakage, however, a simple analysis based on the evolution of the initial size fraction is not sufficient. An analysis taking into account also those broken particles which do not fall out of the initial size range is needed, and this can only be done if the distribution of the progeny particles after a series of fracture events is known. Comminution theory provides a framework for this analysis, which is based on population balances. Let's consider a sample of mate-

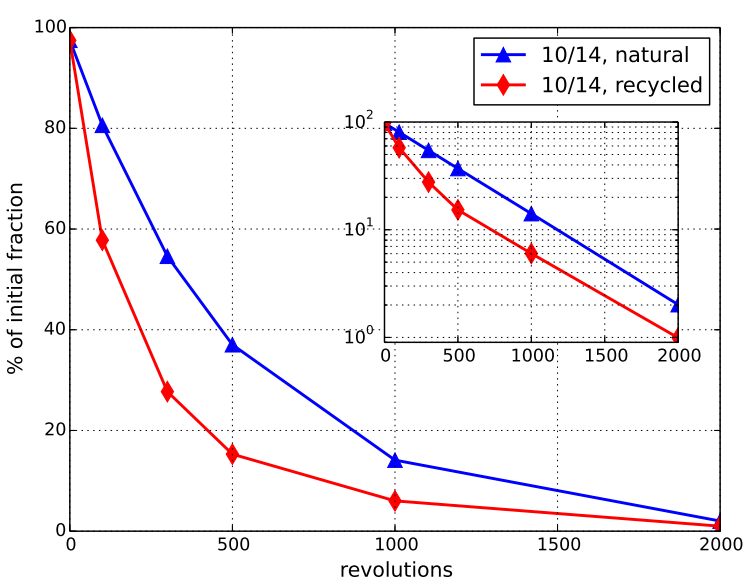

Fig. 10 Evolution of the mass fraction of the initial size fraction during time for two 10/14 mm samples composed respectively of natural and recycled aggregates. The inlet is in lin-log to appreciate the exponential type of evolution.

rial, divided into $\mathrm{N}$ size classes $d_{1}>d_{2}>\ldots>d_{N}$. The population balance for the batch comminution of class $k$ is given by:

$\frac{d w_{k}}{d t}=\sum_{u=1}^{k} w_{u} \Delta B_{k, u} S_{u}-w_{k} S_{k}$,

where $w_{k}$ is the mass fraction of class $k, S_{k}$ is the rate of breakage (also called selection function) of class $k$, and $\Delta B_{k, u}$ corresponds to the fraction of fragments produced by particles of class $u$ which fall into class $k$. $\Delta B_{k, u}$ depends on $B\left(d_{k} ; d_{u}\right)$, which is called the breakage function, and which gives the cumulative size distribution of fragments produced by the fracture of particles of class $u$. By manipulating PSD data (as detailed in Appendix A) it is possible to obtain an estimate for the selection function and the breakage function; this was done to characterize more quantitatively the kinetics of breakage and the repartition of progeny particles.

First, we report on the evolution of the selection function (that is the specific rate of breakage) with the number of revolutions for the initial size range.

The result is displayed in Fig. 11; this confirms that the rate of breakage for $10 / 14 \mathrm{~mm}$ recycled aggregates is high at the beginning and decreases strongly with the number of revolutions, attaining a constant value comparable to natural materials after 1000 revolutions. The rate of breakage of $4 / 6.3 \mathrm{~mm}$ materials appears to be slightly lower, with no great difference between natural and recycled samples; for this size fraction the rate of breakage does not have a remarkable variation with the number of revolutions. The decrease of the rate of breakage with particle size, given the relative size of steel balls and materials, is compatible with the literature (King 2001). 


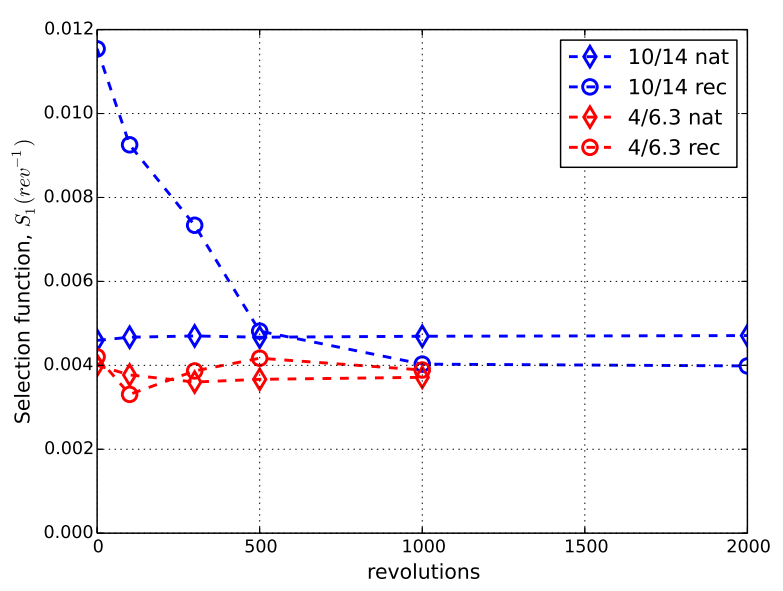

Fig. 11 Estimate of the selection functions vs number of revolutions for natural and recycled aggregates corresponding to intial size ranges of $4 / 6.3 \mathrm{~mm}$ and $10 / 14 \mathrm{~mm}$.

By using the mass variation of size fractions between the feed and the products at 100 revolutions, we can estimate also the breakage function. In particular, the breakage function is defined as the cumulative distribution of progeny particles for a given feed, and is expressed as a function of the ratio between the progeny particle size and the parent particle size. Due to its definition, the breakage function gives information on the repartition of fragments and can therefore help to characterize the mechanisms of fracture. Breakage function estimates for natural and recycled, 4/6.3 $\mathrm{mm}$ and 10/14 $\mathrm{mm}$ aggregates are shown in Fig. 12. First, the qualitative shape of the curves is the same for all materials: data are very well fitted by the classic double Schumann equation:

$B\left(d_{k} ; d_{u}\right)=K\left(\frac{d_{k}}{d_{u}}\right)^{m}+(1-K)\left(\frac{d_{k}}{d_{u}}\right)^{n}$.

This behavior implies that during all the tests fracture is associated with a bimodal distribution of progeny particles: this is usually related to small fragments formed near the points of application of compressive forces and large fragments produced by tensile stresses. This picture corresponds to a cleavage mechanism (see Fig. 1c).

From present data, we can say that the qualitative features of fracture during the tests are the same for the recycled and natural aggregates. There are however quantitative differences: comparing the breakage function for the different materials, at first we notice that different feed particle sizes do not normalize to the same curve. This is not surprising, but could also be an artifact of the estimation procedure. Then, contrary to the selection functions, the largest difference is found between 4/6.3 mm natural and recycled aggregates, while the progenies of natural and recycled 10/14 mm aggregates do not differ so much.

These results allow to better interpret the mass passing $1.6 \mathrm{~mm}$ data: in Fig. 3 we did not see a strong difference between recycled $10 / 14 \mathrm{~mm}$ and $4 / 6.3 \mathrm{~mm}$ recycled aggregates. From figure 12 we can estimate that for short times the fracture of a slightly polydisperse $10 / 14 \mathrm{~mm}$ size fraction of recycled aggregates produces $9.5 \%$ of particles lower than $1.6 \mathrm{~mm}$, while this value is of $29 \%$ for a $4 / 6.3 \mathrm{~mm}$ recycled sample. On the other hand the recycled $10 / 14 \mathrm{~mm}$ sample display a strong difference in rate of breakage with their counterpart at the beginning of the test. The two effects balance each other yielding very close evolutions of the mass passing $1.6 \mathrm{~mm}$. For natural materials breakage rates are similar, so the difference in the selection functions, coupled with the fact that the threshold is kept fixed, are responsible for the difference in the evolution of the mass passing $1.6 \mathrm{~mm}$.

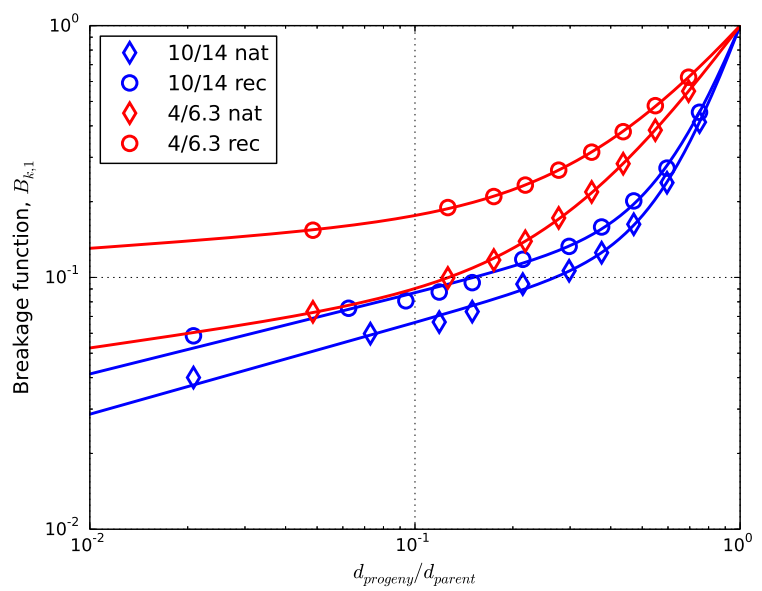

Fig. 12 Estimate of the breakage functions vs number of revolutions for natural and recycled aggregates corresponding to intial size classes of $4 / 6.3 \mathrm{~mm}$ and $10 / 14 \mathrm{~mm}$. Estimates are based on data at 100 revolutions; the solid lines are fit according to Schumann's formula, Eq. 10 .

It is clear that information from both the rate of breakage and the distribution of progeny particles, which can be extracted from PSDs analyses performed at several times, allows to characterize the fragmentation of recycled concrete aggregates. However, if the focus is on the resistance, the evolution of the coarsest fraction alone can be considered as a good indicator of the crushability of the material; the selection function (and even the rescaled selection function which does not need full PSD measurements) gives us information about the resistance of the aggregates during the whole process, with the possibility of estimating the resistance of nat- 
ural components contained in recycled materials if liberation occurs.

In this perspective, in Fig. 13 the selection function for recycled $10 / 14 \mathrm{~mm}$ aggregates is compared to water absorption and density measurements on the coarse fraction. We can see that there is a very good correlation among the three measurements: this supports the idea that the breakage rate of the coarsest fraction can be taken as a measure of the crushability and its dependence on composition. It is therefore very interesting to couple breakage rate measurements with water absorption and particle density data. In this study it was not possible to perform water absorption and particle density measurements on the products of the fragmentation of $4 / 6.3 \mathrm{~mm}$ size fractions. Since the rate of breakage did not vary a lot for those materials, in future works it will be interesting to understand the reason with the required detail by performing a full characterization of the liberation of aggregates.

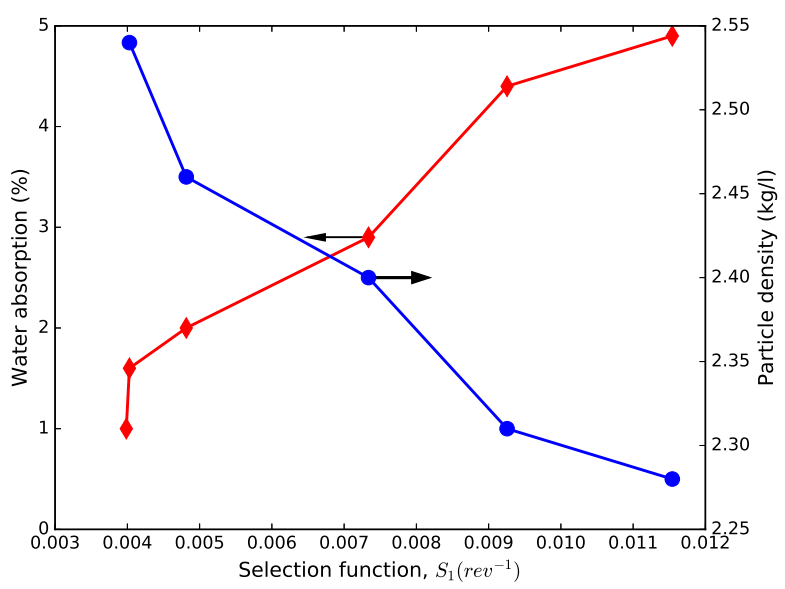

Fig. 13 Water absorption and specific mass vs breakage rate for the $10 / 14 \mathrm{~mm}$ fraction, for a $10 / 14 \mathrm{~mm}$ samples composed of recycled aggregates, at different numbers of revolutions.

\section{Conclusions}

In order to clarify the significance of Los Angeles test when being used with recycled concrete aggregates, three aspects were investigated: the influence of the number of revolutions, the evolution of the full particle size distribution (PSD) and the distribution of mortar in the fractions after the test.

The evolution of the mass passing $1.6 \mathrm{~mm}$ with the number of revolutions showed that recycled concrete aggregate was less resistant to fragmentation compared with natural aggregate and presented a non linear evolution of the indicator with respect to the number of revolutions. However, a more complete analysis of the evolution of the PSD with the number of revolutions suggested that the fracture mechanisms are of the same nature between recycled and natural aggregates. The different behavior during fracture of RCA consisted in mortar which progressively accumulates in smaller fractions, with coarse fractions asymptotically behaving like natural aggregates. This was proved by water absorption and particle density measurements, coupled to the PSD evaluation. This liberation behavior was confirmed by analysis based on comminution modeling which allowed to estimate, for the initial size fraction, the rate of breakage (also called selection function) and the distribution of progeny particles (also called breakage function).

The analysis of the rate of breakage of the coarsest fraction appeared to be a richer indicator of crushability as a function of time and composition than the amount of mass passing $1.6 \mathrm{~mm}$ : its typical evolution allows estimating a rate of breakage which correlates well with indirect measures of composition (water absorption and density). The possible existence of an asymptote in the rate of breakage of the coarsest fraction suggests that the selection function can be used to estimate at the same time the resistance of the recycled aggregate and of its original natural component, and probably give an estimate of the amount of mortar. Then, the estimation of the breakage function for the initial size fraction allowed to better understand fracture mechanisms, and to prove that the same type of fracture occurs for recycled and natural aggregates, though with some quantitative differences.

\section{References}

Akbarnezhad A, Ong K, Tam C, Zhang M (2013) Effects of the Parent Concrete Properties and Crushing Procedure on the Properties of Coarse Recycled Concrete Aggregates. Journal of Materials in Civil Engineering 25(12):1795-1802

Amirkhanian SN, Kaczmarek D, Burati Jr JL (1991) Effects of los angeles abrasion test values on the strengths of laboratory-prepared marshall specimens. Transportation Research Record (1301)

Arulrajah A, Disfani MM, Horpibulsuk S, Suksiripattanapong C, Prongmanee N (2014) Physical properties and shear strength responses of recycled construction and demolition materials in unbound pavement base/subbase applications. Construction and Building Materials 58:245-257

ASTM C131 (2014) Standard test method for resistance to degradation of small-size coarse aggregate by abrasion and impact in the los angeles machine

ASTM C535 (2013) Standard test method for resistance to degradation of large-size coarse aggregate by abrasion and impact in the los angeles machine

Bach H (2013) Evaluation of attrition tests for railway ballast. PhD thesis, Graz University of Technology 
Barbudo A, Agrela F, Ayuso J, Jiménez JR, Poon CS (2012) Statistical analysis of recycled aggregates derived from different sources for sub-base applications. Construction and Building Materials 28(1):129-138

Belin P, Habert G, Thiery M, Roussel N (2014) Cement paste content and water absorption of recycled concrete coarse aggregates. Materials and Structures 47(9):1451-1465

Blengini GA, Garbarino E (2010) Resources and waste management in Turin (Italy): the role of recycled aggregates in the sustainable supply mix. Journal of Cleaner Production 18(10):1021-1030

Bond FC (1952) The third theory of comminution. Trans AIME 193:484-494

Buck A (1973) Recycled concrete. Highway Research Record $430: 1-8$

Cameron DA, Azam AH, Rahman MM (2012) Recycled Clay Masonry and Recycled Concrete Aggregate Blends in Pavement. In: GeoCongress, pp 1532-1541

Commissariat Général au Développement Durable (2011) Waste managed by the building companies: Quantities and management methods in 2008. In: Chiffres et statistiques no.231. Ministère de l'Ecologie du Développement Durable des Transports et du Logement, France

Courard L, Michel F, Delhez P (2010) Use of concrete road recycled aggregates for Roller Compacted Concrete. Construction and Building Materials 24(3):390-395

De Juan MS, Gutiérrez PA (2009) Study on the influence of attached mortar content on the properties of recycled concrete aggregate. Construction and Building Materials 23(2):872877

Diagne M, Tinjum JM, Nokkaew K (2015) The effects of recycled clay brick content on the engineering properties, weathering durability, and resilient modulus of recycled concrete aggregate. Transportation Geotechnics 3:15-23

EN 1097-2 (2010) Tests for mechanical and physical properties of aggregates - part 2: Methods for the determination of resistance to fragmentation

EN 1097-6 (2013) Tests for mechanical and physical properties of aggregates - part 6: Determination of particle density and water absorption

EN 13450 (2002) Aggregates for railway ballast

EN 206-1 (2000) Concrete - part 1: Specification, performance, production and conformity

EN 933-1 (2012) Tests for geometrical properties of aggregates part 1: Determination of particle size distribution - sieving method

Erichsen E (2015) Plotting aggregate degradation results from the Los Angeles test on a triangular diagram: proposal of a new quality ranking for aggregates. Bulletin of Engineering Geology and the Environment 74(2):667-671

Hansen, Torben C and Narud, Henrik (1983) Strength of Recycled Concrete Made From Crushed Concrete Coarse Aggregate. Concrete International 5(01)

Kawano H (1995) The state of reuse of demolished concrete in japan. In: Integrated design and environmental issues in concrete technology: proceedings of the International Workshop 'Rational Design of Concrete Structures under Severe Conditions', E \& FN Spon, London, p 243-249

Kazi A, Al-Molki ME (1982) Empirical relationship between Los Angeles abrasion and aggregate Impact Value tests. In: Proceedings of the 4th IAEG congress, vol 6, pp 293-299

Kick F (1885) Das Gesetz der Proportionalem Widerstand und Seine Anwendung (Principle of Proportional Resistance and Its Application). Leipzig, Germany: Felix

King RP (2001) Modeling and simulation of mineral processing systems. Butterworth-Heinemann
Liu H, Kou S, Lindqvist PA, Lindqvist JE, Åkesson U (2004) Microscope rock texture characterization and simulation of rock aggregate properties. SGU project 60:1362

Mostafa Tavakoli and Parviz Soroushian (1996) Strengths of Recycled Aggregate Concrete Made Using Field-Demolished Concrete as Aggregate. Materials Journal 93(2)

Oikonomou N (2005) Recycled concrete aggregates. Cement and Concrete Research in Greece 27(2):315-318

Paine KA, Dhir RK (2010) Recycled aggregates in concrete: a performance related approach. Magazine of Concrete Research 62(7):519-530

Panet M, Tourenq C (1971) Les essais de granulats. Connaissances actuelles et orientation des recherches. Bulletin de Liaison des Laboratoires des Ponts et Chaussées (5):53

Pasandín A, Pérez I (2014) Characterisation of recycled concrete aggregates when used in asphalt concrete: a technical literature review. European Journal of Environmental and Civil Engineering 19(8):917-930

Rahman MA, Imteaz M, Arulrajah A, Disfani MM (2014) Suitability of recycled construction and demolition aggregates as alternative pipe backfilling materials. Journal of Cleaner Production 66:75-84

Rao A, Jha KN, Misra S (2007) Use of aggregates from recycled construction and demolition waste in concrete. Resources, Conservation and Recycling 50(1):71-81

von Rittinger PR (1867) Zweiter Nachtrag zum Lehrbuch der Aufbereitungskunde, vol 1. Verlag von Ernst und Korn

Tam VW, Tam C (2006) A review on the viable technology for construction waste recycling. Resources, Conservation and Recycling 47(3):209-221

Tavares LM (2007) Chapter 1 Breakage of Single Particles: QuasiStatic, In: Salman AD, Ghadiri M and Hounslow MJ (eds), Handbook of Powder Technology, Elsevier Science B.V., Volume 12, Pages 3-68.

Tuğrul A, Zarif I (1999) Correlation of mineralogical and textural characteristics with engineering properties of selected granitic rocks from Turkey. Engineering Geology 51(4):303-317

Varela E, Vazquez E, Güell A, Barra M, Girbés I, López F, Martínez M, Romero A, Serna P, Tirado A (2011) Gear project e diagnosis of the current recycling situation in spain. In: John V, Vazquez E, Angulo S, Ulsen C (eds) Proceedings of the Second International RILEM Conference on Progress of Recycling in the Built Environment, RILEM Publications SARL, pp 29-38

Wills B, Atkinson K (1993) Some observations on the fracture and liberation of mineral assemblies. Minerals Engineering 6(7):697-706

Yiu LC, Tam VWY, Kotrayothar D (2009) A Simplified Testing Approach for Recycled Coarse Aggregate in Construction. HKIE Transactions 16(4):43-47

Zega C, Villagrán-Zaccardi Y, Di Maio A (2010) Effect of natural coarse aggregate type on the physical and mechanical properties of recycled coarse aggregates. Materials and Structures 43(1-2):195-202

\section{A Determination of the selection and the breakage function of the initial coarse class}

In this appendix we will review the basics of comminution theory which allow us to get a coarse estimate for the rate of breakage and the breakage function for our materials. Consider a sample of material, divided into $\mathrm{N}$ size classes $d_{1}>d_{2}>\ldots>d_{N}$. The 
population balance for the batch comminution of class $k$ is given by:

$\frac{d w_{k}}{d t}=\sum_{u=1}^{k} w_{u} \Delta B_{k, u} S_{u}-w_{k} S_{k}$,

where $w_{k}$ is the mass fraction of class $k, S_{k}$ is the rate of breakage (also called selection function) of class $k$, and $\Delta B_{k, u}$ corresponds to the fraction of fragments produced by particles of class $u$ which fall into class $k$. The latter can be calculated from: $\Delta B_{k, u}=B\left(d_{k-1} ; d_{u}\right)-B\left(d_{k} ; d_{u}\right)$,

where $B\left(d_{k} ; d_{u}\right)$, abbreviated into $B_{k, u}$ in the following, is the breakage function giving the cumulative size distribution of fragments produced by fracture of a particle of class $u$. Typically the shape of $B$ is considered as size independent, i.e. $B\left(d_{k} ; d_{u}\right)=$ $B\left(d_{k} / d_{u}\right)$. The selection function is typically a function of particle size, and is often considered to be independent of $w_{k}$. If we consider a batch process in which all the material is at the beginning in class 1 , for this class we have:

$\frac{d w_{1}}{d t}=w_{1} S_{1}\left(\Delta B_{1,1}-1\right)$,

which means that the loss of material in class 1 corresponds to the fraction of broken particles of this class which have passed the boundary of the class. We can define an effective rate of breakage for the first class $S_{1}^{*}=-S_{1}\left(\Delta B_{1,1}-1\right)$, which can be calculated as:

$S_{1}^{*}=-\frac{d \log w_{1}}{d t}$.

Now, for homogeneous materials $S_{1}^{*}$ is typically a constant; for heterogeneous materials the composition of each size class may vary during the process, modifying the rate of breakage. Eq. 6 can be used in that case to estimate an instantaneous value of the effective rate of breakage. If all the material is at the beginning in the coarsest class, it is possible to estimate the breakage function if data are available for short times. In such a case

$\frac{d w_{k \neq 1}}{d t} \approx w_{1} S_{1} \Delta B_{k, 1}$.

Therefore, considering Eq. 5, we obtain:

$\left.\frac{d w_{k \neq 1}}{d w_{1}}\right|_{t \rightarrow 0}=\frac{\Delta B_{k, 1}}{\Delta B_{1,1}-1}$.

We can define an effective selection function for the coarsest class, which can be calculated from data as:

$B_{k, 1}^{*}=\frac{B_{k, 1}}{1-\Delta B_{1,1}}=\sum_{i=k}^{N-1} \frac{\Delta B_{i, 1}}{1-\Delta B_{1,1}}=-\sum_{i=k}^{N-1} \frac{\Delta w_{i}}{\Delta w_{1}}$.

Given that $B_{1,1}=1,1-\Delta B_{1,1}=B_{2,1}$. We can therefore obtain an estimate for $B_{k, 1}^{*}$ by means of Eq. 9 (which can be applied for short times, after 100 drum revolutions in our study). In order to estimate the original breakage and selection function we can for example proceed by curve fitting. A typical shape for $B_{k, u}$ is the double Schumann equation:

$B\left(d_{k} ; d_{u}\right)=K\left(\frac{d_{k}}{d_{u}}\right)^{m}+(1-K)\left(\frac{d_{k}}{d_{u}}\right)^{n}$.

Therefore the effective breakage function for class 1 can be fitted by

$B_{k, 1}^{*}=\frac{K\left(\frac{d_{k}}{d_{1}}\right)^{m}+(1-K)\left(\frac{d_{k}}{d_{1}}\right)^{n}}{K\left(\frac{d_{2}}{d_{1}}\right)^{m}+(1-K)\left(\frac{d_{2}}{d_{1}}\right)^{n}}$.

The fitting parameters can be used to estimate $B_{2,1}$ and therefore obtain the original breakage and selection functions for the coarsest class by means of:

$B_{k, 1}=B_{k, 1}^{*} B_{2,1}$

$S_{1}=\frac{S_{1}^{*}}{B_{2,1}}$. 